\title{
Development of medical education in Nepal
}

\author{
Dixit $\mathbf{H}$ \\ Principal and Consultant Paediatrician, Kathmandu Medical College
}

\begin{abstract}
The first institution for training health workers started 75 years ago. Further development of teaching / learning institutions, mainly governmental started from the middle of the $20^{\text {th }}$ Century. It was however with the setting up of the Institute of Medicine (IoM) under TU that training programmes for different grades of health manpower were started. The last two decades has seen an explosion of institutions involved in the training of health personnel. This is possibly because of the huge demand of human resources of health (HRH) not only in Nepal, but worldwide. Various grades of HRH are going out of the country and seeking their livelihood elsewhere.
\end{abstract}

Key words: IoM, BPKIHS, PAHS, HRH,

$\mathrm{M}$ edical education in Nepal started about 75 years ago when the Nepal Rajakiya Ayurved Vidyalaya in 1933 was started at Kathmandu for the training of Ayurvedic health workers ${ }^{1}$. The Civil Medical School at Kathmandu, for compounders and dressers who were in fact the basic level health workers for the provision of health care to the people was set up a year later. The next stage was in 1972 when the IoM was started and began the process for the training of different categories of basic, middle and higher levels of Human Resources for Health (HRH). Though the idea for training doctors was first thought about in 1963, the programme for MBBS doctors within the country started later. This course, started after a lot of thought and planning, was community oriented, system based and with integrated teaching. What type of medical services, the people desired, had been determined by doing health surveys in four of the seventy-five districts of $\mathrm{Nepal}^{2}$. These districts, representative of different parts of the country were Tanau, Bara, Dhankuta and Surkhet. Though this course at IoM had the McMaster concept of medical education, all the components thereof were not fully implemented. The training of the MBBS doctors was started in 1978 and Post Graduate training of Masters in General Practice or MDGPs, started in 1982.

Initially only personnel who had been middle level health workers were entitled to sit for a competitive examination to be selected for the MBBS course. Middle level categories, such as health assistants, laboratory technicians, nurses and ayurvedic workers were eligible to compete. As these would be doctors were enrolled into the medical course, there was great discussion as to whether they would be recognised elsewhere in the world. Following visits by inspection teams, the MBBS course of IoM was recognised by the Medical \& Dental Councils of Bangladesh and Pakistan. The Medical Council of India (MCI) however, only recognised it belatedly after a long period. There has been talk too in the past 20 years about the mutual recognition of degrees given by the Universities of the South East Asia Region. In August 1996, a Regional WHO supported meeting was held at IoM when Dr. Karmacharya was Dean, to try to solve the many problems. The then President of the MCI, Dr. Ketan Desai attended and Dr. MA Hadi represented the Medical and Dental Council of Bangladesh. This question of the equivalence of qualifications has till now still not been solved.

After the Jana Andolan in 1989/90, health services education in Nepal developed almost by leaps and bounds. First were BP Koirala Institute of Health Sciences (BPKIHS) as a deemed university in 1993 and then KU subsequently in 1994. Later the PG courses at Bir Hospital and the Valley Group of Hospitals were consolidated as a separate entity called National Academy of Medical Sciences (NAMS). The three universities are all having PG programmes in their courses of studies. In 2009 another deemed university Patan Academy of Health Sciences (PAHS) is expected to take students for MBBS. The Purbanchal University (PU) is on the threshold of starting its own medical school at Itahari. Thus from the single medical school

\section{Correspondence}

Prof. Hemang Dixit

Principal and Consultant Paediatrician,

Kathmandu Medical College

E-mail: h2dixit@gmail.com 
in 1978 we have come to a situation in which we will soon be having by end of 2009 a total of 3 universities and 3 deemed universities having a total of $13+$ (6)* Medical, 5+ (1)* Dental and 3 PG conducting institutions viz. TU, KU and NAMS. The projected $(*)$ six new medical colleges are those of PAHS and PU and four others at Tansen, Chitwan, Rajbiraj and Devadaha. The sole new dental college in the planning stage is that of KIST. These colleges being components of a Public and Private Mix should, with co-operation be of great benefit to the country.

Other grades of HRH such as nurses, health assistants, community health workers are being produced at the, about 200 schools scattered all over the country. These are under the aegis of the Centre for Technical Education \& Vocational Training (CTEVT). What is noticeable with all these institutions all over the country is the demand of teaching / learning facilities and materials. Though of varying standards, what is welcome is production of these within the country.

\section{Standards of Education}

Three different bodies are regularly checking the standards of education of these medical and dental colleges:

1. Higher Technical Education Evaluation and Monitoring Committee.

2. The concerned University

3. Nepal Medical Council

After receiving permission to start the medical college the concerned institution has to undergo yearly visits till it gets permanent recognition. This has helped to maintain standards.

\section{Innovative Teaching}

What is remarkable is that when IoM started its MBBS course in 1978 it departed from the traditional format and took ideas initially from McMaster but later from Maastricht and others. The course was community based, system wise and had integrated teaching. This continued on over the years and when the MBBS course at BPKIHS was started the departure from the traditional to problem-based learning was increased. There were further inputs of Maastricht as BPKIHS became a full member of the Network of the Community Oriented Medical Schools.

With the coming of KU in 1990 and the starting of the first course at Manipal College of Medical Sciences the process of learning that had been laid down continued on a bit further. The full stress in all the KU affiliated medical schools was on the SPICES model, which was basically:

\begin{tabular}{lllll}
\multicolumn{2}{l}{ Mnemonic } & & \\
S & student centred & vs & teacher centred & T \\
P & problem based & vs & information gathering & I \\
I & integrated & vs & discipline based & D \\
C & community based vs & hospital based & H \\
E & elective & vs & uniformed/standard & U \\
S & systematic & vs & apprenticeship & A
\end{tabular}

It was thus only in 1993 that Nepal Medical Council (NMC) brought out its 'Recommendation of Undergraduate Medical Education'3. It also laid down the minimum requirements for setting up medical schools within the country. What may be appreciated is that NMC stipulated that a Medical Education Unit / Dept was an essential component of a medical college $e^{4}$.

Later KU stared the innovative Problem Based Programme at its own School of Medical Sciences at Chaukot / Dhulikhel in Kavre. With the inputs of Harvard Medical School, KU went on to have two tracks of the medical course - the traditional one and the Problem Based at KU School of Medical Sciences (KUSMS).

The implementation of Problem Based Learning was tackled more earnestly at KU School of Medical Sciences (KUSMS) and the result now is that they are trying to encourage its introduction at the medical colleges affiliated to it. It is hoped that besides Kathmandu Medical College, others under KU will also shift towards the new innovative process.

The newly established Patan Academy of Health Sciences has had much input from a number of worldwide institutions, which have been utilising the PBL approach for a number of years and have adequate experience in this field. It is expected that there will be a bridging course prior to candidates entering the planned five years plus one year of internship course of MBBS. Thus it is hoped that the implementation of the PBL approach will be much more effective from now onwards.

\section{Medical Education Departments.}

The idea of Regional Training Centres for Medical Education started in the early seventies. By 1978 there were however only two such centres- one at Perediniya in Sri Lanka and the other at Chulalongkorn in Thailand. WHO SEARO made concentrated efforts to start medical education centres in all countries of the SEAR. Students of individual countries, not getting a place to study medicine in their own, continue to go to adjoining neighbouring countries to study medicine. Doubts have been raised regarding the standard of 
teaching at some of these institutions. Judging by the number of schools being established, there seems to be a great demand but the question remains as to for how long. Mutual recognition has been replaced by licensing examinations. Our students wishing to go abroad sit for USMLE, PLAB and other tests for Australia. MCI has introduced licensing examinations for Indian students who have studied outside the country. We in Nepal have made it mandatory for fresh doctors to sit for a licensing examination irrespective of whether they have qualified within or outside of the country. It seems that mutual recognition of degrees will be a practise of the past.

As far as Nepal was concerned, the Education Support unit was established at IoM in January 1986. Just over a year later it was renamed Education Support Centre with the objective to inculcate the new and old teachers of IoM into the art of teaching. Further development went into the Medical Education Department in 1990 with a further stress into being a teaching / learning centre. A recommendation was made in 1994 for setting up a national centre of Medical / Health Sciences education. This was further stressed upon and recommended for implementation in 1997 but nothing has occurred in the last 11 years. Nepal Medical Council, noting its importance has decreed that each medical college must have its own Medical Education Department.

\section{Standards of Medical Education}

Nepal Medical Council has been giving guidelines on medical education for over thirty years. Is it necessary, effective or even worthwhile? Should we not have examinations even in the clinical sciences? What must be remembered is that standards which have been laid down need to be revised periodically to keep up with the times.
Many years ago, someone I met said that the concept of God is universal and our desire is always to look up to him who is at the very top. He felt that there are different ways to get to the top and what may be the best for one individual may not be the best for others. This applies too to a certain extent in the training of doctors in the healing arts. The various systems of healing existing in the world vary in their methods of instruction. Even the modernised form of medical treatment, which started from a system of apprenticeship with the 'master', went on to the different trades or guilds and ended up by being the academic courses of the Universities. The aim is to produce personnel able to look after the health of one's fellow beings. We in Nepal have a very short history of Health Personnel education. We are fortunate that we in this $21^{\text {st }}$ Century have easy access to widespread information technology and to the Internet or World Wide Web. Using it wisely will ensure rapid knowledge transfer and dissemination from any corner of the earth. We should be able to utilise this opportunity if we are to forge ahead.

\section{Refrences}

1. Dixit H. Nepal's Quest for Health. $3^{\text {rd }}$ Ed. 2005. Educational Publishing House.

2. Rural Health Needs - Tanau, Bara, Dhankuta and Surkhet.

3. Tuladhar TM - Milestones of Nepal Medical Council in Medical Education in Nepal . 1995. Nepal Medical Council / Nepal Medical Association

4. Requirements for starting Medical Colleges. 2003 Nepal Medical Council. 